\title{
Genetic alterations in anaplastic thyroid carcinoma and targeted therapies (Review)
}

\author{
ZONGJUAN LI ${ }^{1 *}$, YANG ZHANG $^{2 *}$, RUONAN WANG $^{1}$, KUN ZOU $^{3}$ and LIJUAN ZOU ${ }^{1}$ \\ ${ }^{1}$ Department of Radiation Oncology, The Second Affiliated Hospital, Dalian Medical University, Dalian, Liaoning 116027; \\ ${ }^{2}$ Department of Radiation Oncology, Yantai Yuhuangding Hospital Affiliated to Qingdao University \\ Medical College, Yantai, Shandong 264000; ${ }^{3}$ Department of Radiation Oncology, The First \\ Affiliated Hospital, Dalian Medical University, Dalian, Liaoning 116011, P.R. China
}

Received May 7, 2018; Accepted June 21, 2019

DOI: $10.3892 /$ etm.2019.7869

\begin{abstract}
Thyroid cancer is the most common type of endocrine malignancy, and its incidence is increasing. Anaplastic thyroid cancer (ATC), referring to undifferentiated subtypes, is considered to be aggressive and associated with poor prognosis. Conventional therapies, including surgery, chemotherapy and radioiodine therapy, have been used for ATC, but these do not provide any significant reduction of the overall mortality rate. The tumorigenesis, development, dedifferentiation and metastasis of ATC are closely associated with the activation of various tyrosine cascades and inactivation of tumor suppressor genes, including B-Raf proto-oncogene, serine/threonine kinase $\mathrm{V}^{\mathrm{V} 600 \mathrm{E}}$, phosphatidylinositol-4,5-bisphosphate 3-kinase catalytic subunit $\alpha$,tumor protein 53 mutations and telomerase reverse transcriptase mutation. These pathways exert their functions individually or through a complex network. Identification of these mutations may provide a deeper understanding of ATC. A variety of tyrosine kinase inhibitors have been successfully employed for controlling ATC growth in vitro and in xenografts. Certain novel compounds are still in clinical trials. Multi-kinase inhibitors provide a novel approach with great potential. This systematic review determined the prevalence of the major genetic alterations and their inhibitors in ATC.
\end{abstract}

Correspondence to: Professor Lijuan Zou, Department of Radiation Oncology, The Second Affiliated Hospital, Dalian Medical University, 467 Zhongshan Road, Shahekou, Dalian, Liaoning 116027, P.R. China

E-mail: zoulijuan1963@sina.com

Miss Kun Zou, Department of Radiation Oncology, The First Affiliated Hospital, Dalian Medical University, 222 Zhongshan Road, Xigang, Dalian, Liaoning 116011, P.R. China

E-mail: zoukun29@163.com

*Contributed equally

Key words: thyroid cancer, mutant p53, phosphatidylinositol4,5-bisphosphate 3-kinase catalytic subunit $\alpha$, telomerase reverse transcriptase, target inhibitor

\section{Contents}

1. Introduction

2. PI3K/Akt/mTOR pathway in ATC

3. PI3K inhibitors

4. mTOR inhibitors

5. Dual PI3K/mTOR inhibitors

6. AKT inhibitors

7. TP53 in ATC

8. Introduction of wild-type p53

9. Enhancement of the functionality of endogenous wild-type p53

10. 'Correction' of mutant p53 protein

11. hTERT and BRAF ${ }^{\mathrm{V} 600 \mathrm{E}}$ in advanced thyroid cancer

12. TERT inhibitors and BRAF inhibitors

13. Other agents and approaches

14. Conclusion

\section{Introduction}

Thyroid cancer is the most prevalent type of endocrine malignancy and accounts for $1 \%$ of cancer cases worldwide. Based on the degree of differentiation, thyroid cancers are categorized as differentiated thyroid cancer [DTC, including papillary thyroid carcinoma (PTC) and follicular thyroid carcinoma], as well as poorly-differentiated thyroid carcinoma (PDTC) and anaplastic thyroid cancer (ATC) (1). Most patients with DTC maybe effectively cured with standard primary treatments and have an excellent prognosis (2). Although ATC only accounts for $2 \%$ of thyroid cancer cases, it is responsible for more than half of all thyroid cancer mortalities due to its aggressive behavior and resistance to conventional therapies $(3,4)$.

Recent molecular pathological studies have indicated that activation of various tyrosine cascades and inactivation of the tumor protein (TP) 53 tumor suppressor gene may induce the progression and dedifferentiation of ATC (5). According to a study on 516 patients from The Cancer Genome Atlas (TCGA) and Memorial Sloan Kettering Cancer Center (MSKCC) database, poorly differentiated thyroid carcinoma (including ATC) had more mutations in TP53, telomerase reverse transcriptase (TERT) and PI3K than PTC. The signaling pathways may exert their functions individually or through synergy with 
other pathways $(6,7)$. Besides conventional chemotherapy, multi-kinase-targeted inhibitors are emerging as novel therapeutic strategies (8). The aim of this review was to determine the prevalence of the major genetic alterations and report on the emerging kinase-targeted therapies in ATC.

\section{PI3K/Akt/mTOR pathway in ATC}

The PI3K pathway has a key role in regulating cell growth, proliferation and survival. This pathway is upregulated in two ways, firstly by the binding of the p 85 subunit of PI3K to the subunits of activated tyrosine residues present on an activated growth factor receptor and secondly via direct recognition and combination of RAS and P110 (9). mTOR is a regulatory protein of the PI3K/Akt/mTOR pathway and its activation results in the phosphorylation of 4E-binding protein (4EBP1) and ribosomal protein $\mathrm{S} 6$ (S6k1) both of which regulate the transcription and translation of critical growth genes (10). Willems et al (11) reported that the activation of mTOR was higher in lymph node metastases than in primary thyroid cancers. Phosphorylated (p)-Akt then activates a variety of downstream factors, including glycogen synthase kinase, Bad, the forkhead box family of transcription factors, p27 and Mdm2. The downstream targets of p-Akt have been demonstrated to increase cell proliferation, motility, protein synthesis and gluconeogenesis, as well as to inhibit apoptosis $(12,13)$. p-Akt also affects the nuclear proteins including transcription factors and nuclear receptors, to form a unique signaling network (14).

The MSKCC and TCGA contains data for 516 thyroid cancer patients (84 PDTCs, 33 ATC cases and 399 PTC cases) and indicated that mutations of PI3K/Akt/mTOR [including mutations of phosphatidylinositol-4,5-bisphosphate 3-kinase catalytic subunit $\alpha$ (PIK3CA) and phosphatase and tens in homolog (PTEN), and of PIK3C2G, PIK3CG,PIK3C3, PIK3R1, PIK3R2, AKT3, TSC subunit 1 (TSC1), TSC2 and mTOR] were more frequent in PDTCs and ATCs than in PTCs (Fig. 1A). Analysis of the association between PI3KCA and overall survival among the 117 PDTC and ATC cases indicated that patients with mutations of PI3KCA had an obviously shorter survival time (10.3 vs. 116.69 months; Fig. 1B and C). Kunstman et al (15) and Landa et al (16) performed next-generation sequencing of thyroid cancer patients and the results revealed that mutations of PI3K/Akt/mTOR were more frequent in ATCs than in other types of thyroid cancer.

All of the above suggests that the PI $3 \mathrm{~K} / \mathrm{mTOR}$ pathway may be closely linked to thyroid cancer. Current research focuses on multiple inhibitors that interfere with different nodes of the PI3K pathway for use in combination with traditional therapy in clinical trials (Fig. 2).

\section{PI3K inhibitors}

NVP-BKM120 (Buparlisib), an inhibitor of pan-class I PI3K, has been proven to have a role in tumor suppression in a variety of cell lines and xenograft models, with or without PI3K alterations (17). NVP-BKM120 has a bioavailability of $>90 \%$ and a half-life of $40 \mathrm{~h}$ according to a study on breast cancer (18). It has been proven that NVP-BKM120 suppresses downstream factors of PI3K, including downregulation of p-Akt and p-S6R and cancer stem markers. A previous study by our group suggested that synergistic action of BKM120 and Prima- $1^{\mathrm{Met}}$ effectively suppressed the proliferation and migration and promoted the differentiation of thyroid cancer cells in vivo and in vitro (19). Radiation therapy is another important treatment for thyroid cancer, but low-dose radiation induces the activation of the PI3K/A kt/mTOR pathway, leading to the occurrence of epithelial-mesenchymal transition (EMT). EMT is characterized by reduced expression of E-cadherin and enhanced cell motility, as well as acquisition of invasive features and metastasis. It has been reported that NVP-BKM120 efficiently inhibits the activation of the PI3K/Akt/mTOR pathway, which increases the number of DNA breaks and promotes the sensitivity to radiotherapy $(20,21)$. NVP-BKM120 is undergoing phase II/III clinical testing for further evaluation (22).

\section{4. mTOR inhibitors}

RAD001 (everolimus), a rapamycin analog, is an allosteric mTORC1 inhibitor. RAD001 has a therapeutic effect in tumors harboring alterations in the mTOR pathway (23). RAD001 has been tested in a phase II clinical trial (24) including 28 patients with progressive metastatic or locally advanced radioactive refractory DTC and 7 patients with ATC. The results indicated that 17 patients (65\%) achieved stable disease (SD) as the best response, with 15 (58\%) exhibiting SD lasting for $>24$ weeks. Furthermore, treatment with RAD001 increased progression-free survival in patients with metastatic cancer. As only 7 patients with ATC were included, it was not possible to draw any definite conclusions. The results of that study on patients with ATC were disappointing, with none of the patients benefitting from treatment. Certain pre-clinical trials evaluating the anti-tumor activity of everolimus, alone or in combination, are ongoing, suggesting that mTOR inhibitors including everolimus may be a promising treatment option for thyroid cancer (25).

\section{Dual PI3K/mTOR inhibitors}

BEZ235, a dual PI3K/mTOR inhibitor, reduces PI3K, mTORC1 and mTORC2 kinase activity, and consistently inactivates downstream signaling factors via competitive binding to the ATP binding domain of these enzymes $(26,27)$. For dual PI3K/mTOR inhibition, BEZ235 has demonstrated a better effect in terms of therapeutic resistance and synergistic effects. BEZ235 has been effectively evaluated in vitro on several thyroid cancer cell lines derived from major pathological types, with ATC exhibiting the greatest sensitivity. BEZ235 generally induces cell cycle arrest at the G0/G1 phase, and also causes apoptosis in the most sensitive thyroid cell lines. The experiments also established that daily treatment with BEZ235 at a dose of $50 \mathrm{mg} / \mathrm{kg}$ significantly reduced the growth of xenograft tumors composed of $8505 \mathrm{C}$ ATC cells, without any toxicity observed (27). In addition, BEZ235 was able to increase the expression of $\mathrm{Na}^{+} / \mathrm{I}^{-}$symporter (NIS) and other thyroid-specific genes, leading to an increase in or the restoration of the sensitivity to radioactive iodine (RAI) (28).

\section{AKT inhibitors}

Akt is a central and essential point in the PI3K pathway, and is therefore a promising target for anti-cancer therapies. Akt 
A

PI3K/Akt/mTOR pathway

\begin{tabular}{|c|c|c|c|}
\hline $\mathrm{K} 3 \mathrm{CA}$ & |ННПН|||||||||||| & PIK3CA & $\|$ \\
\hline & 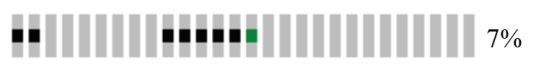 & PTEN & 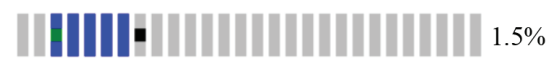 \\
\hline $\mathrm{K} 3 \mathrm{C} 2 \mathrm{C}$ & 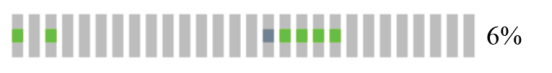 & PIK 3 C2G & 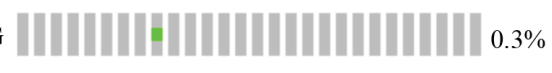 \\
\hline $\mathrm{K} 3 \mathrm{CG}$ & |Н||||||||||| $2.6 \%$ & PIK3 3 CG & \|\| \\
\hline $\mathrm{K} 3 \mathrm{C} 3$ & 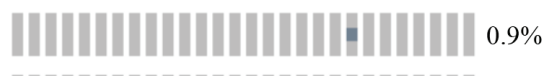 & $\mathrm{c} 3$ & |П|П|||| $0 \%$ \\
\hline & 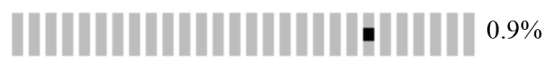 & PIK $3 R 1$ & "H\|\|" \\
\hline PIK3R2 & 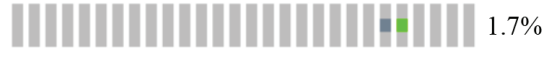 & 颜 PIK3R2 & \|\|$\|_{0.3 \%}$ \\
\hline АKT3 & 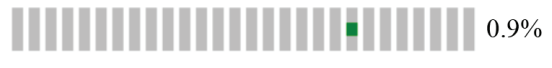 & ét AKT3 & |||||||||||||| \\
\hline $\mathrm{TSC} 1$ & 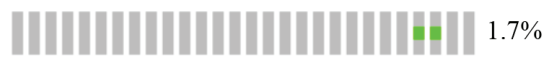 & ${ }^{2} \mathrm{TSCl}$ & IIII $0.8 \%$ \\
\hline $\mathrm{TSC} 2$ & 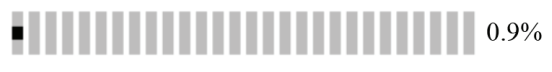 & TSC2 & $0.3 \%$ \\
\hline mTOR & ||||||||||||||||||||| & $\mathrm{mTOR}$ & $1110 \%$ \\
\hline
\end{tabular}

Genetic alteration Amplification Deletion Truncating mutation Missense mutation

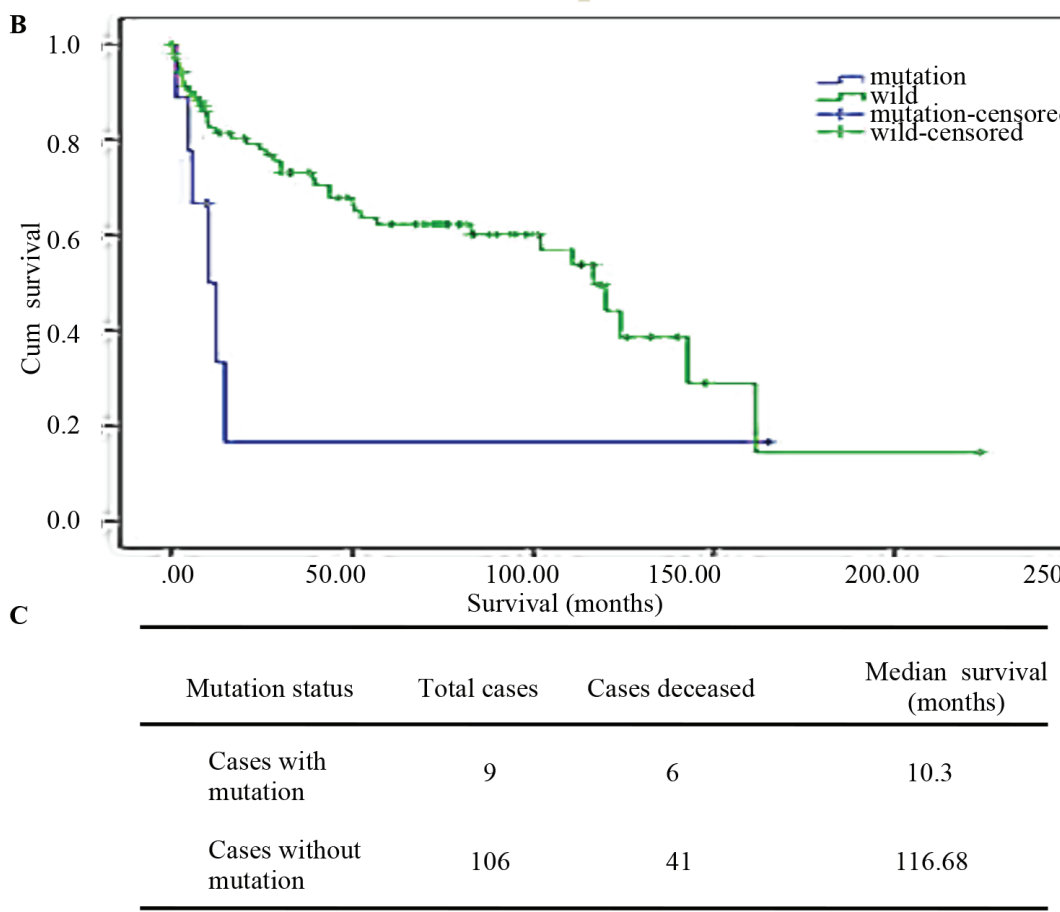

Figure 1. PI3K/Akt/mTOR pathway mutation in thyroid cancers. (A) PI3K/AKT/mTOR pathway (includes PIK3CA, PTEN, PIK3C2G, PIK3CG, PIK3C3, PIK3R1, PIK3R2, AKT3, TSC1, TSC2 and MTOR) mutation in well-differentiated thyroid tumor types (PTC) and those with poor differentiation (PDTC and ATC). (B) Kaplan-Meier survival analysis of 84PDTC and 33 ATC with log-rank P-values indicating significantly shorter survival in mutation cases $(\mathrm{P}=0.044)$. (C) Overall median survival of 117 PDTC and ATC cases. ATC, anaplastic thyroid cancer; Cum, cumulative; wild, wild-type; PTEN, phosphatase and tensin homolog; PIK3CA, phosphatidylinositol-4,5-bisphosphate 3-kinase catalytic subunit $\alpha$; TCGA, The Cancer Genome Atlas; MSKCC, Memorial Sloan Kettering Cancer Center; PTC, papillary thyroid carcinoma; PDTC, poorly differentiated thyroid tumor; TSC1, TSC subunit 1.

inhibitors maybe grouped into various classes, including ATP-competitive inhibitors (GSK690693 and Afuresertib), allosteric inhibitors (MK-2206 and PH-316) and irreversible inhibitors (LL-AF101) (29). MK-2206 is a selective inhibitor of all Akt isoforms, decreasing p-Akt Thr308 and p-Akt Ser473 levels as well as downstream phosphorylation. MK-2206 was demonstrated exert dose- and time-dependent effects on different thyroid cancer cells lines. It potently inhibited the proliferation of all thyroid cancer cells in a low-micromolar range $\left(\mathrm{IC}_{50}\right.$ mostly below or around $\left.0.5 \mu \mathrm{M}\right)$. When used synergistically with temsirolimus, MK2206 was able to completely overcome the side effect of mTOR inhibition of Akt (30) therefore, MK-2206 is a good candidate for further investigation as a treatment for ATC.

\section{TP53 in ATC}

TP53 lies at the center of a large network of apoptosis-, invasion-and stem cell-associated genes. The p53 protein is composed of a core DNA-binding domain (DBD) and regulatory domains, serving as a major barrier against tumorigenesis (31). Of note, numerous in vitro and xenograft models 


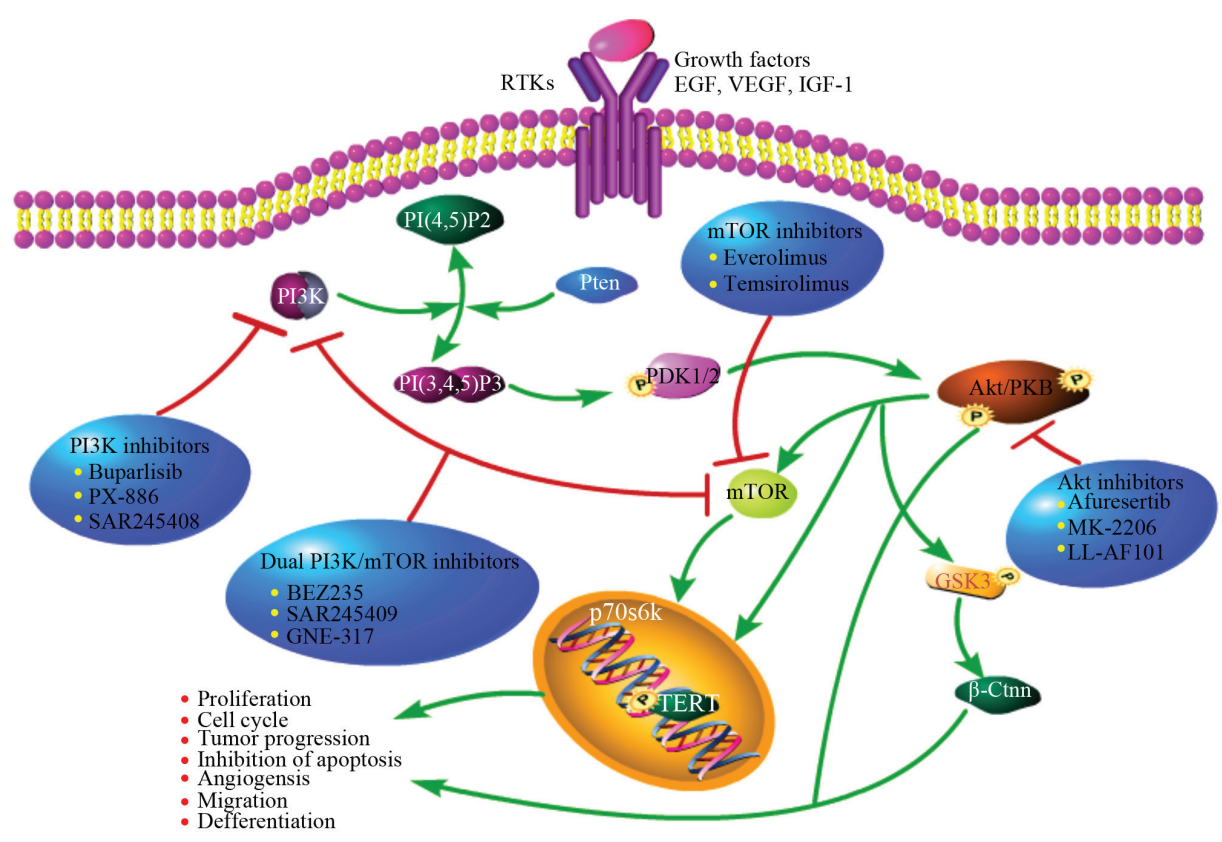

Figure 2. Overview of PI3K/Akt/mTOR activity regulation, downstream effectors and target inhibitors. This pathway is commonly upregulated in tumor cells by upstream stimulation, activating genetic alterations in PI3K, Akt, mTOR, loss of function of PTEN or activation via cross-talk pathways. Specific inhibitors of PI3K, Akt and mTOR may represent a potential and innovative strategy in tumors with overactivation of this pathway. PI3K, phosphatidylinositol-4,5-bisphosphate 3-kinase; mTOR, mammalian target of rapamycin; EGF, epidermal growth factor; VEGF, vascular endothelial growth factor; IGF-1, insulin-like growth factors-1.

have confirmed that p53 mutation not only abolishes the tumor suppressive function, but also often acquires new tumorigenic driver activities. This negative role was termed gain-of-function (GOF). Inactivation of $\mathrm{p} 53$ has been considered a hallmark of advanced thyroid tumors (32). TP53 mutations have been identified in $28.2 \%$ of PTCs and in $1 \%$ of ATCs and PDTCs. Among the 33 ATC and 84 PDTC patients from MSKCC dataset, the mutation group had a median survival time of only 10 months (124.08 in the wild-type TP53 group; Fig. 3A and B). Mutant p53 enhances signaling through receptors such as transforming growth factor $\beta$ receptor, epidermal growth factor receptor and MET. Unlike wild-type p53, mutant p53 protein has been verified to escape proteasome-dependent degradation, leading to its hyper-stabilization in tumors (33). The degradation resistance of mutant p53 presents a fundamental problem for therapeutic intervention in tumors with mutant p53.

Restoration of p53 function is essential for promoting the sensitivity to chemotherapeutic drugs or radiation therapy. This hypothesis is supported by a study in which redifferentiation and restoration of cellular responses to physiological stimuli were achieved after re-expression of wild-type p53 in ATC (34). Table I summarizes the small molecules that restore the function of the tumor suppressor gene $\mathrm{p} 53$.

\section{Introduction of wild-type p53}

Restoration of wild-type p53 function may be achieved by introduction of an intact complementary DNA copy of the p53 gene using a suitable viral vector, in most cases an adenoviral vector [recombinant adenovirus-p53 (Adp53)]. ONYX-015, the most prominent and clinically evaluated replication-competent Adp53 vector, has been proven to have a tumor-specific effect, and proliferates effectively in p53-mutant, but not in p53 wild-type cells (35). Furthermore, suppression of p21 via p21-targeting micro-ribonucleic acids may effectively induce Adp53-mediated apoptosis and autophagy in human cancer cells (36). Subsequent studies demonstrated that a higher clinical efficacy was achieved when ONYX-015 was combined with conventional chemotherapeutic drugs or radiation. Numerous clinical trials have been performed in different types of advanced cancers patients $(37,38)$. However, numerous patients still respond poorly (39). Gendicine (rAd-p53), a first-generation gene therapeutic, has been licensed for clinical use for head and neck malignancies in China. In randomized trials on nasopharyngeal and pancreatic carcinoma, better control was observed when Gendicine (weekly intra-tumoral injections) was combined with radiation or chemoradiation therapy (40). However, to date, these vectors have not been widely used in patients worldwide. The precise mechanism of action and clinical anti-tumor effect of these vectors requires further exploration.

\section{Enhancement of the functionality of endogenous wild-type p53}

As mentioned above, the p53 pathway is most likely also disrupted in a large fraction of wild-type p53-carrying tumors. $\mathrm{Mdm} 2$, a critical negative regulator acting via ubiquitinmediated p53 degradation, is frequently overexpressed in wild-type TP53-carrying tumors, leading to resistance to p53 gene therapy for cancer (41). Furthermore, mutant p53 is overexpressed in numerous tumors due to a lack of sufficient amounts of Mdm2 to trigger p53 degradation. For these reasons, Mdm2 has been an important therapeutic target. Different strategies for targeting Mdm2 and/or inhibition of p53-Mdm2 binding 


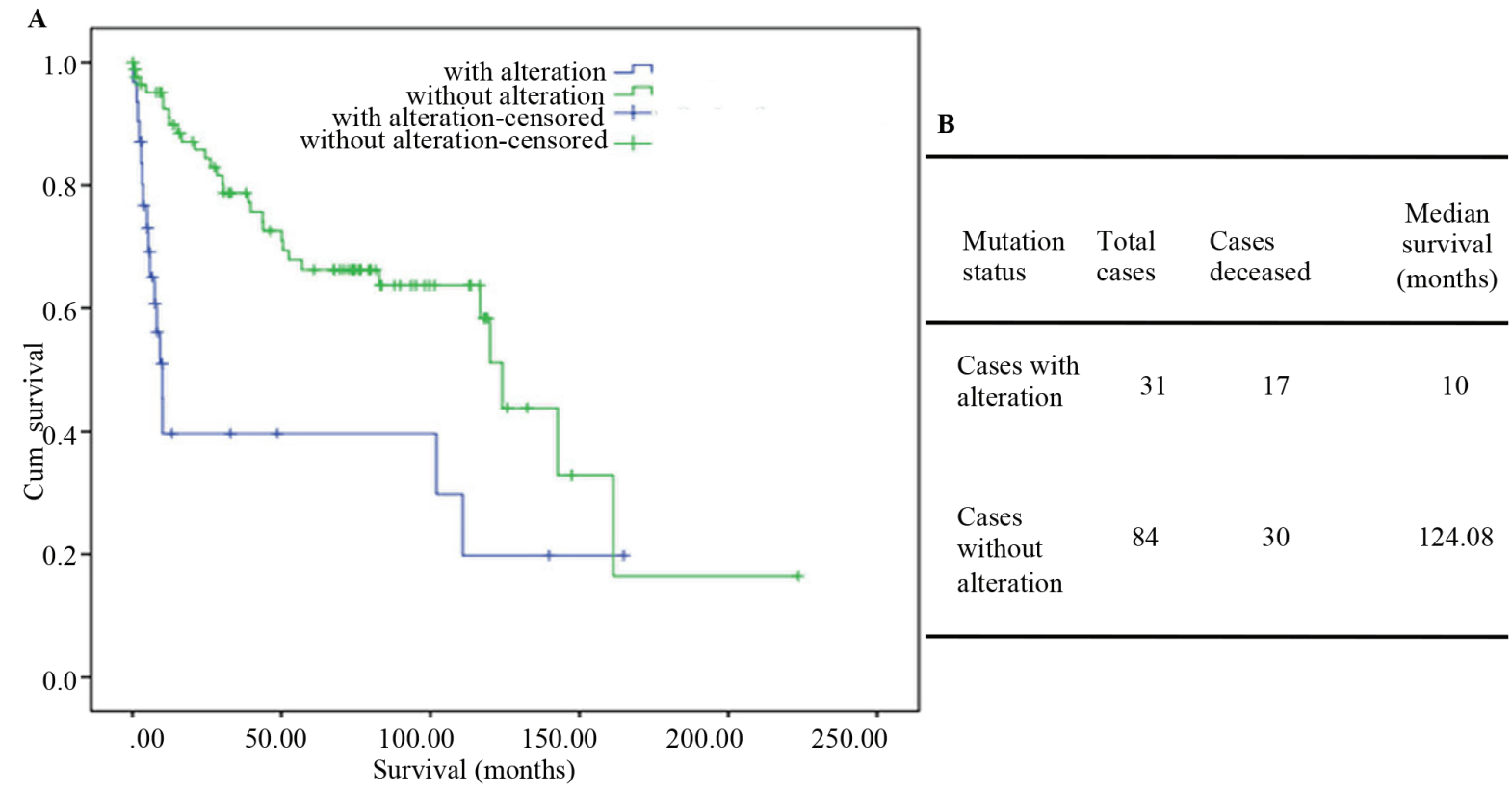

Figure 3. Contingency analysis of tumor protein 53 mutations in thyroid cancers and its targeted therapy. (A) Kaplan-Meier survival analysis of 117 PDTCs and ATCs with log-rank P-values indicating significantly shorter survival incases with a mutation $\left(\mathrm{P}=8.826 \times 10^{5}\right)$. (B) Overall median survival analysis of 117 PDTC and ATC cases. PDTC, poorly differentiated thyroid tumor; ATC, anaplastic thyroid cancer; Cum, cumulative.

have been designed, including Nutlins, reactivation of p53 and induction of tumor cell apoptosis (RITA) and inhibitor of Hdm2 HLI98ubiquitin ligase (HLI 373), which have the ability to increase p53 levels and transcriptional activity (42). Nutlin-3a stabilizes and activates $\mathrm{p} 53$ by blocking p53 binding to $\mathrm{Mdm} 2$, leading to the expression of downstream genes of $\mathrm{p} 53$, including $\mathrm{p} 21, \mathrm{BAX}$ and $\mathrm{p} 53$ upregulated modulator of apoptosis (43). RITA binds to the N-terminus of p53 and causes a configurable change, resulting in accumulation of p53 and upregulation of its target genes. RITA induces apoptosis in wild-type p53-harboring cancer cells, but has little side effects on normal cells (44). The availability of these therapies raises hope for the treatment of wild-type TP53-carrying tumors, with fewer side effects than traditional chemotherapeutic drugs.

\section{0. 'Correction' of mutant p53 protein}

As a result of the unfolding of the DBD, mutant p53 loses its role as a tumor suppressor gene and promotes the development of tumor progression. Therefore, pharmacological compounds to reactivate mutant p53 through changing it to the wild-type conformation and activating its transcription have been developed. These small-molecular drugs, including CP-31398, WR1065, PRIMA-1, PRIMA-1 ${ }^{\text {MET }}$ (APR-246), Ellipticine and MIRA-1, have demonstrated positive effects in cancer, including induction of massive apoptosis, inhibition of invasion and tumor stem cell suppression (45). PRIMA- $1^{\mathrm{MET}}$ is able to not only restore the wild-type conformation of mutant $\mathrm{p} 53$, but also that of mutant $\mathrm{N}$-terminal transactivation domain of TAp63 $\gamma($ TAp63 $\gamma$ ) and N-terminal transactivation domain

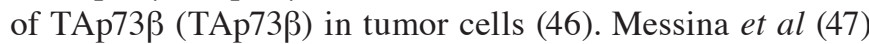
successfully validated that PRIMA- $1^{\text {Met }}$ prevented the GOF effect of mutant p53 and increased the expression of thyroid-specific differentiation markers, including $\mathrm{Tg}$ and NIS, in thyroid cancer cells. PRIMA- $1^{\mathrm{Met}}$ is less effective in wild-type or null p53 thyroid cell lines (BC-PAP and Hth-74 cell viability was significantly reduced at $1 \mu \mathrm{M}$; by contrast, Prima-1 at up to $20 \mu \mathrm{M}$ had no effect on TPC-1 and SW-1736 cells). The use of PRIMA-1 ${ }^{\text {Met }}$ in combination with irradiation and novel targeted tyrosine kinase inhibitors is a novel research hotspot.

\section{Human TERT and B-Raf proto-oncogene, serine/threonine kinase $(\mathrm{BRAF})^{\mathrm{V} 600 \mathrm{E}}$ in advanced thyroid cancer}

Telomerase has a key role in cellular immortality and tumorigenesis. Its catalytic subunit is TERT. Accumulating evidence indicates that TERT promoter mutations are associated with aggressive, metastatic and thyroid stem cell phenotypes $(48,49)$. In the dataset of TGCA database, $~ 40 \%$ of PDTCs and $73 \%$ of ATCs harbored TERT promoter mutations as compared with 9\% of PTCs. In addition, TERT promoter mutations were rarely detected in normal parenchyma or in benign lesions $(50,51)$. BRAF, a member of the RAF family, is a serine-threonine kinase. The $\mathrm{BRAF}^{\mathrm{V} 600 \mathrm{E}}$ mutation, a crucial stimulator of the mitogen-activated protein kinase pathway, is associated with the radioiodine resistance due to block of NIS $\left(\mathrm{Na}^{+} / \mathrm{I}^{-}\right)$ symporter expression. BRAF ${ }^{\mathrm{V} 600 \mathrm{E}}$ is more frequently encountered in the dedifferentiated subtype (52). TERT promoter mutation is closely combined with $\mathrm{BRAF}^{\mathrm{V} 600 \mathrm{E}}$ and RAS mutations. Studies have indicated that the coexistence of somatic mutations, $\mathrm{BRAF}^{\mathrm{V} 600 \mathrm{E}}$ and TERT C228T, is strongly associated with aggressive phenotypes, poor prognosis and recurrence of ATC (53). Analysis of the clinical data of the 84 PDTC and 33 ATC cases from MSKCC revealed that co-existence of BRAF and TERT mutations has a synergistic effect on aggressiveness 
Table I. Compounds that induce reactivation of mutant p53.

\begin{tabular}{lll}
\hline Type of drug & \multicolumn{1}{c}{ Drug } & \multicolumn{1}{c}{ Mechanism } \\
\hline Adenovirus gene therapy & $\begin{array}{l}\text { Advexin } \\
\text { ONYX-015 } \\
\text { CP-31398 }\end{array}$ & $\begin{array}{l}\text { Exogenous import and increase of wide-type p53 } \\
\text { expression } \\
\text { Stabilize the DNA-binding core domain induce } \\
\text { conformational change }\end{array}$ \\
Compounds that induce reactivation of mutant p53 & PRIMA-1 & Bind to thiol groups in the core domain and \\
& PRIMA-1 & restore wide-type conformation \\
RITA & Restore p53 transcriptional activity \\
17-AAG & Hsp90 inhibitors, increase the mutant p53 \\
degradation
\end{tabular}

Hsp, heat shock protein; HDAC, histone deacetylase; RITA/NSC 652287; 17-AAG/Tanespimycin; LBH589/Panobinostat/NVP-LBH589; SAHA/Vorinostat, suberanilo hydroxamic acid.

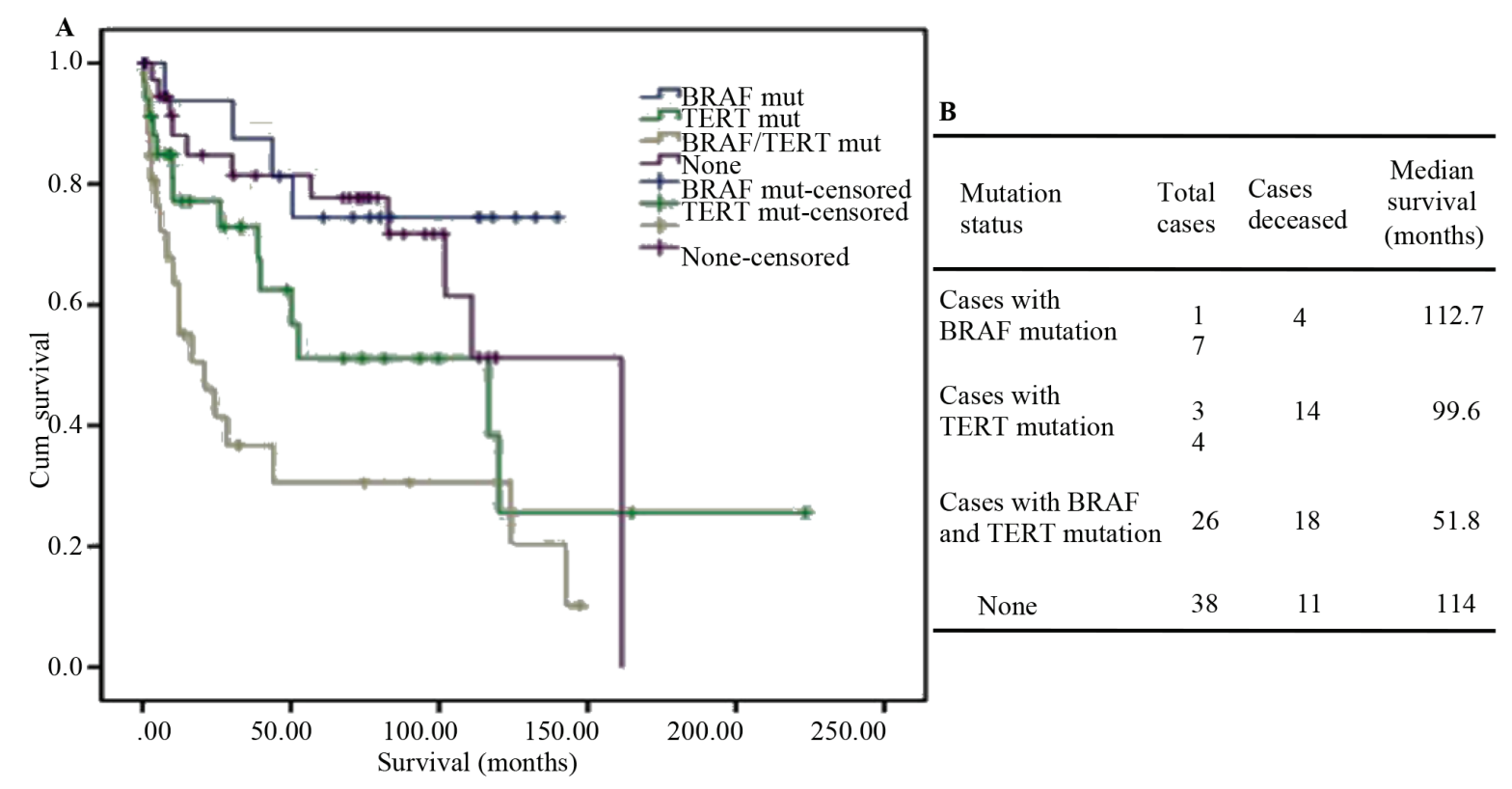

Figure 4. TERT and BRAF mutations in thyroid cancers. (A) Kaplan-Meier survival in PDTCs and ATCs with log-rank P-values (P=0.001). (B) Overall median survival analysis of 117 PDTC and ATC cases. PDTC, poorly differentiated thyroid tumor; ATC, anaplastic thyroid cancer; Cum, cumulative; BRAF, B-Raf proto-oncogene, serine/threonine kinase; TERT, telomerase reverse transcriptase; mut, mutation.

in thyroid carcinoma development. Tumors with both mutations are associated with a high risk of recurrence and shorter overall survival (Fig. 4A and B). Charles et al (54) reported that in the mouse model, PIK3CA was unable to drive thyroid tumorigenesis independently; however, in mice with both PIK3CA and BRAF ${ }^{\mathrm{V} 600 \mathrm{E}}$ mutations, ATC was observed. Of note, in ATC cases featuring BRAF ${ }^{\mathrm{V} 600 \mathrm{E}}$ in combination with PIK3CA or TP53 mutations, few, if any, mutations in other known ATC-associated genes were observed. The mechanism resulting in progression from DTC to ATC has been a subject of frequent study with accumulation of mutations in recognized malignancy-associated genes identified. Therefore, combination of multiple targeted drugs may achieve an effective breakthrough in the treatment of ATC.

\section{TERT inhibitors and BRAF inhibitors}

Vemurafenib (PLX4032) and Dabrafenib (GSK2118436), highly selective for BRAF ${ }^{\mathrm{V} 600 \mathrm{E}}$-mutant cells, have been approved by the US Food and Drug Administration for melanoma therapy (55). The first report of using vemurafenib to treat metastatic papillary thyroid carcinoma was in 2013. Vemurafenib appears to have a promising clinical efficacy in patients with metastatic PTC (56). In a phase II clinical trial, 51 patients (patients with RAI-refractory PTC) were enrolled. Treatment with BRAF inhibitors for redifferentiation and RAI reuptake in $\mathrm{BRAF}^{\mathrm{V} 600 \mathrm{E}}$-mutant thyroid cancer was also assessed. The clinical results suggested that the effect was better at first use (57). Marten and Gudena (58) reported on an ATC patient 
with an early clinical response, demonstrating a decrease in the subcutaneous metastasis, but follow-up computed tomography at 2 months after initiation of vemurafenib revealed rapid progression of the disease with metastases to the central nervous system and esophagus and progression of pulmonary metastasis. Other BRAF inhibitors, including PLX-4720 and MLN2480, are also being tested in the clinic, but have not been evaluated in thyroid cancer. Clinical data indicate that these inhibitors significantly improve response rates and overall survival in patients with $\mathrm{BRAF}^{\mathrm{V} 600 \mathrm{E}}$-mutant metastatic melanoma $(59,60)$. Maggisano et al $(61)$ proved that inhibition of TERT expression by small interfering RNA significantly depressed the proliferation and invasion of ATC cells. BIBR1532, a selective telomerase inhibitor, decreases native and recombinant human telomerase activity, leading to senescence of human cancer cells. A study by $\mathrm{Bu}$ et al (62) reported that BIBR1532 effectively decreased the invasion, migration and angiogenesis of PTC cells in vivo and in vitro. However, at present, studies assessing the efficacy of BIBR1532 in the treatment of ATC are rare.

\section{Other agents and approaches}

$\mathrm{NF}-\kappa \mathrm{B}$ allows thyroid cancer cells to acquire invasive properties and undergo metastasis by upregulating the expression of matrix metalloproteinases and urokinase-type plasminogen activator (63). Triptolide has been used in preclinical studies on ATC, and has demonstrated an inhibitory effect on angiogenesis and invasion (64). More clinical research is required to evaluate the synergistic effect with other chemotherapeutic agents for thyroid cancer. The Wnt- $\beta$-catenin signaling pathway is associated with cell adhesion and differentiation (65). Accumulation of $\beta$-catenin may induce nuclear transport and combine with certain transcription factors, which may activate the transcription of downstream factors, including c-myc and cyclin D1. The Wnt- $\beta$-catenin pathway may also regulate the level of cyclin D1, which is associated with lymph node metastases in thyroid cancer patients. Dickkopf-1, a selective inhibitor of the Wnt- $\beta$-catenin pathway, effectively inhibits the proliferation and migration of several thyroid cancer cell lines by regulating Wnt- $\beta$-catenin and E-cadherin expression (66). Certain genes regulate each other and form networks to produce a biological effect. Further signaling pathways are also associated with the development and progression of ATC. Sorafenib is a multikinase inhibitor that targets vascular endothelial growth factor receptor (VEGFR), platelet-derived growth factor receptor (PDGFR) and RAF. In the phase II trial of sorafenib, 10 patients with ATC were enrolled and no objective responses were observed (67). Another two trials assessing sorafenib in thyroid carcinomas included six ATC patients and similarly no responses were achieved $(68,69)$. These results call into question the benefit of this agent in ATC patients. Another study involved 15 ATC patients treated with pazopanib (a multikinase inhibitor targeted on VEGFR, PDGFR and c-kit) in a single-arm, phase II study, with no responses obtained according to the Response Evaluation Criteria in Solid Tumors (70). Lenvatinib, a newer, small-molecule VEGFR inhibitor, was tested in differentiated thyroid cancer, medullary thyroid carcinoma and ATC in a phase II study. Only 11 patients with ATC were recruited; however, the results were encouraging, with three patients exhibiting a partial response according to the Response Evaluation Criteria in Solid Tumors, seven with SD and one patient exhibiting progression of disease (71). Lenvatinib has been approved in the USA for the treatment of DTC, but it is approved for all subtypes of thyroid cancer in Japan (67).

Genomic and epigenetic alterations are now being exploited as molecular targets in thyroid cancer treatment. The abnormalities of the histones in post-translational modification have been demonstrated in thyroid cancer development, and they are regarded as promising molecular targets for the patients that are resistant to conventional therapies. Compounds/drugs that reverse the effects of histone modifications by modulating the pattern of histone acetylation/methylation have been tested in preclinical models of thyroid cancer to identify their effects on tumor cell proliferation and/or invasiveness, and their ability to re-differentiate tumor cells and restore their ability to accumulate radioactive iodine $(72,73)$.

\section{Conclusion}

Precision medical therapy is an exciting technique for individualized tumor treatment based on the patient's features and tumor characteristics. ATC is one of the most aggressive human cancer types and is associated with a low survival rate. Dysfunction of signaling pathways may increase the proliferation, dedifferentiation and metastasis of thyroid cancer. Inhibition of protein tyrosine kinases has been indicated to hold great promise. These drugs may not only provide a better understanding of tumor biological characteristics, but also more optimistic outcomes in the future. Combination of tyrosine kinases inhibitors with traditional radiotherapy and chemotherapy may represent an improved treatment strategy.

\section{Acknowledgements}

Not applicable.

\section{Funding}

The present study was supported by funds from the National Natural Science Foundation of China (grant nos. 81703904 KZ and 81473452 LZ) and the Education Department of Liaoning Province, China ('the Program for Distinguished Professor of Liaoning Province').

\section{Availability of data and materials}

The datasets used and/or analyzed during the present study are available from the corresponding author on reasonable request.

\section{Authors' contributions}

$\mathrm{LZ}$ and $\mathrm{ZL}$ contributed to the design and conception of the study, and revised it carefully for important intellectual content. $\mathrm{YZ}$ was responsible for acquiring the data by screening the papers identified on Pubmed and TCGA. RW revised the study critically for important intellectual content. KZ and ZL were involved in drafting the study. YZ analyzed and interpreted the data. All authors read and approved the final manuscript. 


\section{Ethics approval and consent to participate}

Not applicable.

\section{Patient consent for publication}

Not applicable.

\section{Competing interests}

The authors declare that they have no competing interests.

\section{References}

1. O'Neill JP and Shaha AR: Anaplastic thyroid cancer. Oral Oncol 49: 702-706, 2013

2. Jin S, Borkhuu O, Bao W and Yang YT: Signaling pathways in thyroid cancer and their therapeutic implications. J Clin Med Res 8: 284-296, 2016.

3. Hsu KT, Yu XM, Audhya AW, Jaume JC, Lloyd RV, Miyamoto S, Prolla TA and Chen H: Novel approaches in anaplastic thyroid cancer therapy. Oncologist 19: 1148-1155, 2014.

4. Keutgen XM, Sadowski SM and Kebebew E: Management of anaplastic thyroid cancer. Gland Surg 4: 44-51, 2015.

5. Saini S, Maker AV, Burman KD and Prabhakar BS: Genetic aberrations and alterations in signaling cascades implicated in the pathogenesis of anaplastic thyroid cancer. Biochim Biophys Acta Rev Cancer, 2018 (Epub ahead of print).

6. Guerra A, Di Crescenzo V, Garzi A, Cinelli M, Carlomagno C, Tonacchera M, Zeppa P and Vitale M: Genetic mutations in the treatment of anaplastic thyroid cancer: A systematic review. BMC Surg 13 (Suppl 2): S44, 2013.

7. Xu B and Ghossein R: Genomic landscape of poorly differentiated and anaplastic thyroid carcinoma. Endocr Pathol 27: 205-212, 2016

8. Perri F, Pezzullo L, Chiofalo MG, Lastoria S, Di Gennaro F, Scarpati GD and Caponigro F: Targeted therapy: A new hope for thyroid carcinomas. Crit Rev Oncol Hematol 94: 55-63, 2015.

9. Bartholomeusz $\mathrm{C}$ and Gonzalez-Angulo AM: Targeting the PI3K signaling pathway in cancer therapy. Expert Opin Ther Targets 16: 121-130, 2012.

10. Saji M and Ringel MD: The PI3K-Akt-mTOR pathway in initiation and progression of thyroid tumors. Mol Cell Endocrinol 321: 20-28, 2010.

11. Willems L, Tamburini J, Chapuis N, Lacombe C, Mayeux P and Bouscary D: PI3K and mTOR signaling pathways in cancer: New data on targeted therapies. Curr Oncol Rep 14: 129-138, 2012.

12. Cao F, Zhang C, Han W, Gao XJ, Ma J, Hu YW, Gu X, Ding HZ, Zhu LX and Liu Q: p-Akt as a potential poor prognostic factor for gastric cancer: A systematic review and meta-analysis. Oncotarget 8: 59878-59888, 2017.

13. Phyu SM and Smith TAD: Combination treatment of cancer cells with pan-Akt and pan-mTOR inhibitors: Effects on cell cycle distribution, p-Akt expression level and radiolabelled-choline incorporation. Invest New Drugs 37: 424-430, 2019.

14. Xing M: Genetic alterations in the phosphatidylinositol-3 kinase/Akt pathway in thyroid cancer. Thyroid 20: 697-706, 2010.

15. KunstmanJW,JuhlinCC,GohG,BrownTC,Stenman A,Healy JM, Rubinstein JC, Choi M, Kiss N, Nelson-Williams C, et al: Characterization of the mutational landscape of anaplastic thyroid cancer via whole-exome sequencing. Hum Mol Genet 24: 2318-2329, 2015.

16. Landa I, Ibrahimpasic T, Boucai L, Sinha R, Knauf JA, Shah RH, Dogan S, Ricarte-Filho JC, Krishnamoorthy GP, Xu B, et al: Genomic and transcriptomic hallmarks of poorly differentiated and anaplastic thyroid cancers. J Clin Invest 126: 1052-1066, 2016.

17. Maira SM, Pecchi S, Huang A, Burger M, Knapp M, Sterker D, Schnell C, Guthy D, Nagel T, Wiesmann M, et al: Identification and characterization of NVP-BKM120, an orally available pan-class I PI3-kinase inhibitor. Mol Cancer Ther 11: 317-328, 2012.

18. Sirohi B, Rastogi S and Dawood S: Buparlisib in breast cancer. Future Oncol 11: 1463-1470, 2015.
19. Li Z, Xu X,Li Y,Zou K, Zhang Z, Xu X, Liao Y,Zhao X, Jiang W, $\mathrm{Yu}$ W, et al: Synergistic antitumor effect of BKM120 with prima-1met via inhibiting PI3K/AKT/mTOR and CPSF4/hTERT signaling and reactivating mutant P53. Cell Physiol Biochem 45: 1772-1786, 2018

20. Chang L, Graham PH, Hao J, Ni J, Bucci J, Cozzi PJ, Kearsley JH and Li Y: Acquisition of epithelial-mesenchymal transition and cancer stem cell phenotypes is associated with activation of the $\mathrm{PI} 3 \mathrm{~K} / \mathrm{Akt} / \mathrm{mTOR}$ pathway in prostate cancer radioresistance. Cell Death Dis 4: e875, 2013.

21. Chang L, Graham PH, Hao J, Ni J, Bucci J, Cozzi PJ, Kearsley JH and Li Y: PI3K/Akt/mTOR pathway inhibitors enhance radiosensitivity in radioresistant prostate cancer cells through inducing apoptosis, reducing autophagy, suppressing NHEJ and HR repair pathways. Cell Death Dis 5: e1437,2014.

22. Massacesi C, Di Tomaso E, Urban P, Germa C, Quadt C, Trandafir L, Aimone P, Fretault N, Dharan B, Tavorath R and Hirawat S: PI3K inhibitors as new cancer therapeutics: Implications for clinical trial design. Onco Targets Ther 9: 203-210, 2016

23. Saran U, Foti M and Dufour JF: Cellular and molecular effects of the mTOR inhibitor everolimus. Clin Sci (Lond) 129: 895-914, 2015.

24. Schneider TC, de Wit D, Links TP, van Erp NP, van der Hoeven JJ, Gelderblom H, Roozen IC, Bos M, Corver WE, van Wezel T, et al: Everolimus in patients with advanced follicular-derived thyroid cancer: Results of a phase II clinical trial. J Clin Endocrinol Metab 102: 698-707, 2017.

25. Onoda N, Nakamura M, Aomatsu N, Noda S, Kashiwagi S, Kurata K, Uchino S and Hirakawa K: Significant cytostatic effect of everolimus on a gefitinib-resistant anaplastic thyroid cancer cell line harboring PI3KCA gene mutation. Mol Clin Oncol 3: 522-526, 2015.

26. Yi H, Ye X, Long B, Ye T, Zhang L, Yan F, Yang Y and Li L: Inhibition of the AKT/mTOR pathway augments the anticancer effects of sorafenib in thyroid cancer. Cancer Biother Radiopharm 32: 176-183, 2017.

27. Lin SF, Huang YY, Lin JD, Chou TC, Hsueh C and Wong RJ: Utility of a PI3K/mTOR inhibitor (NVP-BEZ235) for thyroid cancer therapy. PLoS One 7: e46726, 2012.

28. Petrulea MS, Plantinga TS, Smit JW, Georgescu CE and Netea-Maier RT: PI3K/Akt/mTOR: A promising therapeutic target for non-medullary thyroid carcinoma. Cancer Treat Rev 41: 707-713, 2015 .

29. Nitulescu GM, Margina D, Juzenas P, Peng Q, Olaru OT, Saloustros E, Fenga C, Spandidos DA, Libra M and Tsatsakis AM: Akt inhibitors in cancer treatment: The long journey from drug discovery to clinical use (Review). Int J Oncol 48: 869-885, 2016.

30. Liu R, Liu D, Trink E, Bojdani E, Ning G and Xing M: The akt-specific inhibitor MK2206 selectively inhibits thyroid cancer cells harboring mutations that can activate the PI3K/Akt pathway. J Clin Endocrinol Metab 96: E577-E585, 2011.

31. Pflaum J, Schlosser S and Muller M: P53 family and cellular stress responses in cancer. Front Oncol 4: 285, 2014.

32. Parrales A and Iwakuma T: Targeting oncogenic mutant $\mathrm{p} 53$ for cancer therapy. Front Oncol 5: 288, 2015.

33. Maslon MM and Hupp TR: Drug discovery and mutant p53. Trends Cell Biol 20: 542-555, 2010.

34. Bullock AN and Fersht AR: Rescuing the function of mutant $\mathrm{p} 53$. Nat Rev Cancer 1: 68-76, 2001.

35. Wiman KG: Strategies for therapeutic targeting of the p53 pathway in cancer. Cell Death Differ 13: 921-926, 2006.

36. Larson C, Oronsky B, Scicinski J, Fanger GR, Stirn M, Oronsky A and Reid TR: Going viral: A review of replication-selective oncolytic adenoviruses. Oncotarget 6: 19976-19989, 2015.

37. Galanis E, Okuno SH, Nascimento AG, Lewis BD, Lee RA, Oliveira AM, Sloan JA, Atherton P, Edmonson JH, Erlichman C, et al: Phase I-II trial of ONYX-015 in combination with MAP chemotherapy in patients with advanced sarcomas. Gene Ther 12: 437-445, 2005.

38. Makower D, Rozenblit A, Kaufman H, Edelman M, Lane ME, Zwiebel J, Haynes H and Wadler S: Phase II clinical trial of intralesional administration of the oncolytic adenovirus ONYX-015 in patients with hepatobiliary tumors with correlative p53 studies. Clin Cancer Res 9: 693-702, 2003.

39. Chen GX, Zhang S, He XH, Liu SY, Ma C and Zou XP: Clinical utility of recombinant adenoviral human p53 gene therapy: Current perspectives. Onco Targets Ther 7: 1901-1909, 2014.

40. Li J, Pan J, Zhu X, Su Y, Bao L, Qiu S, Zou C, Cai Y, Wu J and Tham IW: Recombinant adenovirus-p53 (Gendicine) sensitizes a pancreatic carcinoma cell line to radiation. Chin J Cancer Res 25: 715-721, 2013 
41. Wade M, Li YC and Wahl GM: MDM2, MDMX and p53 in oncogenesis and cancer therapy. Nat Rev Cancer 13: 83-96, 2013.

42. Oren M, Tal P and Rotter V: Targeting mutant p53 for cancer therapy. Aging (Albany NY) 8: 1159-1160, 2016.

43. Selivanova G: Wild type p53 reactivation: From lab bench to clinic. FEBS Lett 588: 2628-2638, 2014.

44. Urso L, Calabrese F, Favaretto A, Conte P and Pasello G: Critical review about MDM2 in cancer: Possible role in malignant mesothelioma and implications for treatment. Crit Rev Oncol Hematol 97: 220-230, 2016.

45. Puca R, Nardinocchi L, Porru M, Simon AJ, Rechavi G, Leonetti C, Givol D and D'Orazi G: Restoring p53 active conformation by zinc increases the response of mutant p53 tumor cells to anticancer drugs. Cell Cycle 10: 1679-1689, 2011.

46. Bykov VJ and Wiman KG: Mutant $\mathrm{p} 53$ reactivation by small molecules makes its way to the clinic. FEBS Lett 588: 2622-2627, 2014.

47. Messina RL, Sanfilippo M, Vella V, Pandini G, Vigneri P, Nicolosi ML, Gianì F, Vigneri R and Frasca F: Reactivation of p53 mutants by prima-1 [corrected] in thyroid cancer cells. Int J Cancer 130: 2259-2270, 2012.

48. Liu X, Bishop J, Shan Y, Pai S, Liu D, Murugan AK, Sun H, El-Naggar AK and Xing M: Highly prevalent TERT promoter mutations in aggressive thyroid cancers. Endocr-Relat Cancer 20 603-610, 2013.

49. Melo M, da Rocha AG, Vinagre J, Batista R, Peixoto J, Tavares C, Celestino R, Almeida A, Salgado C, Eloy C, et al: TERT promoter mutations are a major indicator of poor outcome in differentiated thyroid carcinomas. J Clin Endocrinol Metab 99: E754-E765, 2014.

50. Liu R and Xing M: TERT promoter mutations in thyroid cancer. Endocr-Relat Cancer 23: R143-R155, 2016.

51. Jin A, Xu J and Wang Y: The role of TERT promoter mutations in postoperative and preoperative diagnosis and prognosis in thyroid cancer. Medicine (Baltimore) 97: e11548, 2018.

52. Dong H, Shen WZ, Yan YJ, Yi JL and Zhang L: Effects of BRAF(V600E) mutation on $\mathrm{Na}(+) / \mathrm{I}(-)$ symporter expression in papillary thyroid carcinoma. J Huazhong Uni Sci Technolog. Med Sci 36: 77-81, 2016.

53. Shi X, Liu R, Qu S, Zhu G, Bishop J, Liu X, Sun H, Shan Z, Wang E, Luo Y, et al: Association of TERT promoter mutation 1,295,228 C>T with BRAF V600E mutation, older patient age, and distant metastasis in anaplastic thyroid cancer. J Clin Endocrinol Metab 100: E632-E637, 2015.

54. Charles RP, Silva J, Iezza G, Phillips WA and McMahon M: Activating BRAF and PIK3CA mutations cooperate to promote anaplastic thyroid carcinogenesis. Mol Cancer Res 12: 979-986, 2014.

55. Zhang W: BRAF inhibitors: The current and the future. Curr Opin Pharmacol 23: 68-73, 2015.

56. Kim KB, Cabanillas ME, Lazar AJ, Williams MD, Sanders DL, Ilagan JL, Nolop K, Lee RJ and Sherman SI: Clinical responses to vemurafenib in patients with metastatic papillary thyroid cancer harboring BRAF(V600E) mutation. Thyroid 23: 1277-1283, 2013.

57. Brose MS, Cabanillas ME, Cohen EE, Wirth LJ, Riehl T, Yue H, Sherman SI and Sherman EJ: Vemurafenib in patients with BRAF(V600E)-positive metastatic or unresectable papillary thyroid cancer refractory to radioactive iodine: A non-randomised, multicentre, open-label, phase 2 trial. Lancet Oncol 17: 1272-1282, 2016

58. Marten KA and Gudena VK: Use of vemurafenib in anaplastic thyroid carcinoma: A case report. Cancer Biol Ther 16: $1430-1433,2015$
59. Cabanillas ME, Patel A, Danysh BP, Dadu R, Kopetz S and Falchook G: BRAF inhibitors: Experience in thyroid cancer and general review of toxicity. Horm Cancer 6: 21-36, 2015.

60. Lim AM, Taylor GR, Fellowes A, Cameron L, Lee B, Hicks RJ, McArthur GA, Angel C, Solomon B and Rischin D: BRAF Inhibition in BRAFV600E-Positive Anaplastic Thyroid Carcinoma. J Natl Compr Canc Netw 14: 249-254, 2016.

61. Maggisano V, Celano M, Lombardo GE, Lepore SM, Sponziello M, Rosignolo F, Verrienti A, Baldan F, Puxeddu E, Durante C, et al: Silencing of hTERT blocks growth and migration of anaplastic thyroid cancer cells. Mol Cell Endocrinol 448: 34-40, 2017.

62. Bu R, Siraj AK, Divya SP, Kong Y, Parvathareddy SK, Al-Rasheed M, Al-Obaisi KAS, Victoria IG, Al-Sobhi SS, Al-Dawish M, et al: Telomerase reverse transcriptase mutations are independent predictor of disease-free survival in middle eastern papillary thyroid cancer. Int J Cancer 142: 2028-2039, 2018.

63. Namba H, Saenko V and Yamashita S: Nuclear factor-kB in thyroid carcinogenesis and progression: A novel therapeutic target for advanced thyroid cancer. Arq Bras Endocrinol Metabol 51: 843-851, 2007.

64. Zhu W, He S, Li Y, Qiu P, Shu M, Ou Y, Zhou Y, Leng T, Xie J, Zheng X, et al: Anti-angiogenic activity of triptolide in anaplastic thyroid carcinoma is mediated by targeting vascular endothelial and tumor cells. Vascul Pharmacol 52: 46-54, 2010.

65. Sastre-Perona A and Santisteban P: Wnt-independent role of $\beta$-catenin in thyroid cell proliferation and differentiation. Mol Endocrinol 28: 681-695, 2014.

66. Wang L, Shao YY and Ballock RT: Thyroid hormone interacts with the Wnt/beta-catenin signaling pathway in the terminal differentiation of growth plate chondrocytes. J Bone Miner Res 22: 1988-1995, 2007.

67. Ito Y, Onoda N, Ito KI, Sugitani I, Takahashi S, Yamaguchi I, Kabu K and Tsukada K: Sorafenib in japanese patients with locally advanced or metastatic medullary thyroid carcinoma and anaplastic thyroid carcinoma. Thyroid 27: 1142-1148, 2017.

68. Gupta-Abramson V, Troxel AB, Nellore A, Puttaswamy K, Redlinger M, Ransone K, Mandel SJ, Flaherty KT, Loevner LA, O'Dwyer PJ and Brose MS: Phase II trial of sorafenib in advanced thyroid cancer. J Clin Oncol 26: 4714-4719, 2008.

69. Kloos RT, Ringel MD, Knopp MV, Hall NC, King M, Stevens R, Liang J, Wakely PE Jr, Vasko VV, Saji M, et al: Phase II trial of sorafenib in metastatic thyroid cancer. J Clin Oncol 27: 1675-1684, 2009

70. Bible KC, Suman VJ, Menefee ME, Smallidge RC, Molina JR, Maples WJ, Karlin NJ, Traynor AM, Kumar P, Goh BC, et al: A multiinstitutional phase 2 trial of pazopanib monotherapy in advanced anaplastic thyroid cancer. J Clin Endocrinol Metab 97: 3179-3184, 2012

71. Takahashi S, Kiyota N, Yamazaki T, Chayahara N, Nakano K, Inagaki L, Toda K, Enokida T, Minami H, Imamura Y, et al: A Phase II study of the safety and efficacy of lenvatinib in patients with advanced thyroid cancer. Future Oncol 15: 717-726, 2019.

72. Sasanakietkul T, Murtha TD, Javid M, Korah R and Carling T: Epigenetic modifications in poorly differentiated and anaplastic thyroid cancer. Mol Cell Endocrinol 469: 23-37, 2018.

73. Celano M, Mio C, Sponziello M, Verrienti A, Bulotta S, Durante C, Damante G and Russo D: Targeting post-translational histone modifications for the treatment of non-medullary thyroid cancer. Mol Cell Endocrinol 469: 38-47, 2018. 